\title{
Phytosterol Variability in Almond Germplasm
}

\author{
Álvaro Fernández-Cuesta \\ Instituto de Agricultura Sostenible, Consejo Superior de Investigaciones Científicas (IAS-CSIC), \\ Alameda del Obispo s/n, 14004 Córdoba, Spain
}

\author{
Ossama Kodad and Rafel Socias i Company ${ }^{1}$ \\ Unidad de Fruticultura, Centro de Investigación y Tecnología Agroalimentaria de Aragón (CITA), \\ Av. Montañana 930, 50059 Zaragoza, Spain
}

\author{
Leonardo Velasco \\ Instituto de Agricultura Sostenible, Consejo Superior de Investigaciones Científicas (IAS-CSIC), \\ Alameda del Obispo s/n, 14004 Córdoba, Spain
}

\begin{abstract}
Additional Index words. Prunus amygdalus, fruit quality, kernel composition, oil quality
Abstract. Phytosterols are important dietary components that contribute to reducing serum cholesterol levels. The objective of this research was to assess genetic diversity for total content and profile of free and esterified phytosterols in a world germplasm collection of almond [Prunus amygdalus Batsch; syn. $P$. dulcis (Mill.) D.A. Webb]. Steryl glycosides and acylated steryl glycosides were not measured. Fruit from 160 almond accessions were collected in 2009 and 2010. Kernel phytosterol content ranged from 1126 to $2769 \mathrm{mg} \cdot \mathrm{kg}^{-1}$ in 2009 and from 1191 to $2777 \mathrm{mg} \cdot \mathrm{kg}^{-1} \mathrm{in}$ 2010. The phytosterol fraction was mainly made up of $\beta$-sitosterol (from $59.1 \%$ to $84.1 \%$ in 2009 and from $55.9 \%$ to $84.6 \%$ in 2010 ) and $\Delta^{5}$-avenasterol (from $8.9 \%$ to $25.4 \%$ in 2009 and from $8.5 \%$ to $28.2 \%$ in 2010 ). Significant genotypic effects were observed for kernel phytosterol content and concentration of major phytosterols. Kernel oil content was positively correlated with kernel phytosterol content in both years. The results suggested that almond germplasm contains genetic variability for both phytosterol content and profile that can be used for developing cultivars with increased levels of phytosterols and contrasting phytosterol profiles. Positive correlation between kernel phytosterol content and kernel oil content suggests the feasibility of simultaneous selection for both traits.
\end{abstract}

Phytosterols or plant sterols are natural constituents of plants. They resemble mammalian cholesterol, both in their chemical structure and their biological function (Piironen et al., 2000). Phytosterols regulate the fluidity and permeability of membranes and also play many other functions in plants, for example as precursors of brassinosteroids, an important group of plant hormones involved in many aspects of plant growth (Hartmann, 1998).

Phytosterols are also important dietary components. Vegetable oils and oil-based products are the richest dietary sources of phytosterols followed by cereal grains, cereal-based products, and nuts (Piironen et al., 2000). Sterols in foods exist as free sterols, fatty acid esters, steryl glycosides, and acylated steryl glycosides (Phillips et al., 2005a). Because of the similarity in the chemical structures of phytosterols and cholesterol, dietary phytosterols reduce intestinal absorption of both dietary and endogenously produced cholesterol, thus reducing serum cholesterol levels (Plat and Mensink, 2005). Because of their cholesterol-lowering properties, phytosterol-derived products such as phytostanol esters have become important ingredients in a wide range of functional foods (Bacchetti et al., 2011).

Received for publication 4 June 2012. Accepted for publication 27 July 2012 This work was supported by the Spanish grants AGL2010-22197-C02-01 and INIA-RF2008-00027, the Research Group A12 of Aragón, and Junta de Andalucía support program to research groups (PAI-AGR-118).

Technical assistance by P. Nieto, J.M. Ansón, O. Frontera, and J. Búbal is gratefully acknowledged.

${ }^{1}$ Corresponding author. E-mail: rsocias@aragon.es.
Almond is the most important tree nut crop in terms of commercial production, which is limited to areas characterized by a Mediterranean climate (Kester and Asay, 1975). Kernel quality has become an important criterion for modern almond cultivars (Socias i Company et al., 2008). Almond germplasm collections have been evaluated for variation in kernel quality traits such as oil content, fatty acid composition (Kodad et al., 2011), and tocopherol content (Kodad et al., 2006). However, there is little information on the variability in phytosterol content in almond germplasm, because the literature only provides results from analyses of commercial almond samples. For example, the analysis of a single sample of almond kernels from a local market (Normén et al., 2007) revealed a phytosterol content of $2080 \mathrm{mg} \cdot \mathrm{kg}^{-1}$. Another study on four different samples of almond kernels from the U.S. market (Phillips et al., 2005 b) reported an average phytosterol content of 1990 $\mathrm{mg} \cdot \mathrm{kg}^{-1}$ (from 1930 to $2080 \mathrm{mg} \cdot \mathrm{kg}^{-1}$ ). Similarly, the analysis of three almond samples from the U.S. market (Robbins et al., 2011) showed an average kernel phytosterol content of $2107 \mathrm{mg} \cdot \mathrm{kg}^{-1}$. The U.S. Department of Agriculture (USDA, 2011) National Nutrient Database reports a kernel phytosterol content of $1720 \mathrm{mg} \cdot \mathrm{kg}^{-1}$. Oil phytosterol levels between 2178 and $2750 \mathrm{mg} \cdot \mathrm{kg}^{-1}$ have been reported for raw almond oils (Miraliakbari and Shahidi, 2008), whereas a phytosterol content of $1999 \mathrm{mg} \cdot \mathrm{kg}^{-1}$ has been reported for commercial almond oil (Dulf et al., 2010). The USDA (2011) National Nutrient Database reports an almond oil phytosterol content of $2660 \mathrm{mg} \cdot \mathrm{kg}^{-1}$. Phillips et al. (2005a) found that $78 \%$ of the phytosterols in almonds are in the form of free and esterified sterols, whereas the remaining $22 \%$ are in the form of steryl glycosides and acylated steryl glycosides. The latter compounds have similar 
cholesterol-lowering properties to free and esterified phytosterols (Lin et al., 2009). However, their relevance for oil quality is limited, because very low levels of steryl glycosides and acylated steryl glycosides are extracted by conventional hexane extraction (Moreau et al., 2003).

There are some discrepancies in the literature about the composition of almond phytosterols. Although all the studies have identified $\beta$-sitosterol as the predominant phytosterol in almond, they differ in the proportions of the other phytosterols. Several studies (Dulf et al., 2010; Normén et al., 2007; Phillips et al., 2005a, 2005b; Robbins et al., 2011) have reported a phytosterol fraction mainly made up of $\beta$-sitosterol (from $72.1 \%$ to $83.9 \%$ ) and $\Delta^{5}$-avenasterol (from $9.9 \%$ to $12.9 \%$ ) and to a lesser extent campesterol $(2.5 \%$ to $3.4 \%)$ and stigmasterol ( $1.6 \%$ to $3.4 \%)$. However, other studies have reported different phytosterol profiles characterized by absence or lower levels of $\Delta^{5}$-avenasterol (Cherif et al., 2009; Maguire et al., 2004; Miraliakbari and Shahidi, 2008).

One of the most important world collections of almond cultivars is located at Centro de Investigación y Tecnología Agroalimentaria (CITA) of Aragón, Spain, with $\approx 250$ accessions introduced from all over the world (Espiau et al., 2002). This collection shows a very large variability reflecting the wide genetic diversity of almond (Socias i Company and Felipe, 1992). The objective of this research was to assess genetic diversity for total content and profile of free and esterified phytosterols in the CITA world germplasm collection.

\section{Materials and Methods}

Plant material. The study was conducted on 160 almond accessions of the CITA world germplasm collection. The accessions are maintained as living plants grafted on the almond $\times$ peach [Prunus persica (L.) Batsch] hybrid clonal rootstock INRA GF-677 using standard management practices (Espiau et al., 2002).

Sample Collection And PReparation. Twenty nuts per accession from open pollination were harvested in 2009 and 2010 at the mature stage when fruit mesocarp was fully dried and split along the fruit suture and peduncle abscission was complete. After blanching, the kernels were ground in a laboratory mill and stored until analysis at $4{ }^{\circ} \mathrm{C}$ for a maximum of $60 \mathrm{~d}$.

Determination of OIL Content. Oil was extracted from 4 to $5 \mathrm{~g}$ of ground almond kernel in a commercial fat extractor (Soxtec Avanti 2055; Tecator, Barcelona, Spain) for 2 h using petroleum ether as a solvent and keeping the heating source at $135{ }^{\circ} \mathrm{C}$ (Kodad and Socias i Company, 2008). The oil content was expressed as the difference in weight of the dried kernel flour sample before and after extraction.

Analysis of Phytosterol Content. Phytosterol content was analyzed in two replicates per sample following a previously described procedure for the analysis of free and esterified phytosterols (Fernández-Cuesta et al., 2012). In short, $200 \mathrm{mg}$ of almond flour was placed in $10-\mathrm{mL}$ propylene tubes and $200 \mu \mathrm{L}$ of an internal standard solution prepared by dissolving cholesterol (99\% purity, reference C8667; Sigma-Aldrich, St. Louis, MO) in hexane-ethanol $(3: 2)$ solution at a concentration of $0.1 \%$. Alkaline hydrolysis was performed by adding $2 \mathrm{~mL}$ of a solution of potassium hydroxide dissolved in ethanol at a concentration of $2 \%$. Phytosterols were extracted by vortexing with $1 \mathrm{~mL}$ hexane and $1.5 \mathrm{~mL}$ water. The upper hexane layer was transferred to $2-\mathrm{mL}$ glass vials that were maintained in an oven at $37.5^{\circ} \mathrm{C}$ overnight. Fifty microliters of hexane and $50 \mu \mathrm{L}$ of silylating mixture composed of pyridine:hexamethyldisilazane:trimethylchlorosilane $(9: 3: 1$ by volume, Silan-Sterol-1, reference 355650.0922; Panreac Química, Barcelona, Spain) were added to the dried pellets and the vials were left at room temperature for $15 \mathrm{~min}$. The solution was transferred to $2-\mathrm{mL}$ vials containing $200-\mu \mathrm{L}$ inserts and centrifuged at $2594 g_{\mathrm{n}}$ for $10 \mathrm{~min}$ (Unicen 21; Ortoalresa, Madrid, Spain). The vials were capped and conserved at $-20{ }^{\circ} \mathrm{C}$. Gas chromatographic analysis was performed on a gas chromatograph (Clarus 600; Perkin Elmer, Waltham, MA) equipped with a ZB5 capillary column (i.d. $=0.25 \mathrm{~mm}$, length $=30 \mathrm{~m}$, film thickness $=0.10 \mu \mathrm{m}$; Phenomenex, Torrance, CA). Hydrogen was used as carrier gas at a pressure of $125 \mathrm{kPa}$. The split injector and flame ionization detector were maintained at $320{ }^{\circ} \mathrm{C}$. The oven thermal regime was the following: the initial temperature of $240{ }^{\circ} \mathrm{C}$ was increased at $5^{\circ} \mathrm{C} \cdot \mathrm{min}^{-1}$ to a final temperature of $265^{\circ} \mathrm{C}$ and held for $10 \mathrm{~min}$. Total analytical time was $15 \mathrm{~min}$. Peak identification was conducted at the reference laboratory of the Instituto de la Grasa, Seville, Spain. Kernel phytosterol content was expressed as milligrams per kilogram of kernel. Oil phytosterol content, expressed as milligrams per kilogram of kernel oil, was estimated from kernel phytosterol content and kernel oil content using the following formula:

$$
\begin{aligned}
& \text { oil phytosterol content } \\
& =(\text { kernel phytosterol content } \times 100) / \text { oil content }
\end{aligned}
$$

Such estimation represents the maximum expected phytosterol content in the raw oil, although the actual content will depend on the efficiency of the extraction system. The concentration of individual phytosterols was expressed as percentage of total free and esterified phytosterols.

Statistical anAlyses. Data were analyzed by the General Linear Model procedure of SPSS Statistics (Version 17.0; IBM Corp., Armonk, NY). Analysis of variance was performed with genotypes as fixed factors and years as random factors. Mean values were analyzed by Duncan's multiple range test.

\section{Results}

Considering all accessions, phytosterol content (free and esterified phytosterols) in the kernel averaged $1904 \mathrm{mg} \cdot \mathrm{kg}^{-1}$ (from 1126 to $2769 \mathrm{mg} \cdot \mathrm{kg}^{-1}$ ) in 2009 and $1861 \mathrm{mg} \cdot \mathrm{kg}^{-1}$ (from 1191 to $2777 \mathrm{mg} \cdot \mathrm{kg}^{-1}$ ) in 2010 . Kernel oil content averaged $60.7 \%$ (from $53.9 \%$ to $69.2 \%$ ) in 2009 and $59.9 \%$ (from $47.2 \%$ to $66.7 \%$ ) in 2010. Oil phytosterol content, calculated from phytosterol and oil contents in the kernel, averaged $3131 \mathrm{mg} \cdot \mathrm{kg}^{-1}$ (from 2013 to $4497 \mathrm{mg} \cdot \mathrm{kg}^{-1}$ ) in 2009 and $3108 \mathrm{mg} \cdot \mathrm{kg}^{-1}$ (from 1898 to $4554 \mathrm{mg} \cdot \mathrm{kg}^{-1}$ ) in 2010 (Table 1). The phytosterol fraction was mainly made up of $\beta$-sitosterol $(72.4 \%$ in 2009 and $73.9 \%$ in 2010) and $\Delta^{5}$-avenasterol (14.8\% in 2009 and $16.2 \%$ in 2010), which together accounted for $87.2 \%$ and $90.1 \%$ phytosterols in 2009 and 2010, respectively. Other phytosterols detected in minor amounts were campesterol (2.7\% in 2009 and $2.8 \%$ in 2010$)$, stigmasterol $(0.8 \%$ in 2009 and $0.7 \%$ in 2010$)$, $\Delta^{7}$-campesterol (3.2\% in 2009 and $2.5 \%$ in 2010), clerosterol (1.3\% in 2009 and $1.2 \%$ in 2010), sitostanol (0.7\% in 2009 and $0.2 \%$ in 2010$), \Delta^{5,24}$-stigmastadienol $(0.9 \%$ in 2009 and $0.3 \%$ in 2010), $\Delta^{7}$-stigmastenol (1.5\% in 2009 and $1.0 \%$ in 2010 ), and $\Delta^{7}$-avenasterol (1.8\% in 2009 and $1.1 \%$ in 2010) (Table 1). The 
Table 1. Average values and ranges of variation for phytosterol content in the kernel, kernel oil content, phytosterol content in the kernel oil, and concentrations of individual phytosterols in almond kernels from 160 accessions collected in 2009 and 2010.

\begin{tabular}{|c|c|c|c|c|c|c|}
\hline \multirow[b]{2}{*}{ Trait } & \multicolumn{3}{|c|}{2009} & \multicolumn{3}{|c|}{2010} \\
\hline & Mean & Minimum & Maximum & Mean & Minimum & Maximum \\
\hline Kernel oil (mg. $\left.\mathrm{kg}^{-1} \mathrm{kernel}\right)$ & 60.7 & 53.9 & 69.2 & 59.9 & 47.2 & 66.7 \\
\hline Kernel phytosterol (\% kernel) & 1904 & 1126 & 2769 & 1861 & 1191 & 2777 \\
\hline Oil phytosterol $\left(\mathrm{mg} \cdot \mathrm{kg}^{-1} \text { oil }\right)^{\mathrm{z}}$ & 3132 & 2013 & 4497 & 3108 & 1898 & 4554 \\
\hline Campesterol (\% phytosterols) & 2.7 & 1.4 & 5.8 & 2.8 & 1.5 & 6.1 \\
\hline Stigmasterol (\% phytosterols) & 0.8 & 0.3 & 2.9 & 0.7 & 0.2 & 2.6 \\
\hline$\Delta^{7}$-Campesterol ( $\%$ phytosterols $)$ & 3.2 & 0.9 & 7.5 & 2.5 & 0.1 & 9.8 \\
\hline Clerosterol (\% phytosterols) & 1.3 & 0.5 & 2.6 & 1.2 & 0.4 & 2.8 \\
\hline$\beta$-Sitosterol (\% phytosterols) & 72.4 & 59.1 & 84.1 & 73.9 & 55.9 & 84.6 \\
\hline Sitostanol (\% phytosterols) & 0.7 & 0.0 & 1.6 & 0.2 & 0.0 & 1.4 \\
\hline$\Delta^{5}$-Avenasterol (\% phytosterols) & 14.8 & 8.9 & 25.4 & 16.2 & 8.5 & 28.2 \\
\hline$\Delta^{5,24}$-Stigmastadienol ( $\%$ phytosterols) & 0.9 & 0.0 & 2.7 & 0.3 & 0.0 & 1.8 \\
\hline$\Delta^{7}$-Stigmastenol (\% phytosterols) & 1.5 & 0.1 & 4.8 & 1.0 & 0.1 & 3.5 \\
\hline$\Delta^{7}$-Avenasterol (\% phytosterols) & 1.8 & 0.2 & 4.6 & 1.1 & 0.4 & 3.8 \\
\hline
\end{tabular}

${ }^{\mathrm{z}}$ Calculated from kernel phytosterol content and kernel oil content.

collection contained large variability in the phytosterol profiles with the concentration of $\beta$-sitosterol ranging from $59.1 \%$ to $84.1 \%$ in 2009 and from $55.9 \%$ to $84.6 \%$ in 2010 and the concentration of $\Delta^{5}$-avenasterol ranging from $8.9 \%$ to $25.4 \%$ in 2009 and from $8.5 \%$ to $28.2 \%$ in 2010 (Table 1). Supplemental information with the results for all accessions is available online (CITA, 2012).

The analysis of variance showed differences among genotypes for kernel oil content, kernel phytosterol content, oil phytosterol content, and the concentration of individual phytosterols, except for $\Delta^{7}$-campesterol and clerosterol (Table 2). Year effect was significant for the concentration of individual phytosterols, except for clerosterol, but not for kernel oil content, kernel phytosterol content, or oil phytosterol content. Genotype $\times$ year interaction was significant for kernel oil content, kernel and oil phytosterol content, and concentration of some phytosterols such as campesterol, $\Delta^{7}$-campesterol, clerosterol, $\beta$-sitosterol, and $\Delta^{5}$-avenasterol.

Taking into account both years, 'Elvira' had significantly $(P<0.05)$ lower kernel phytosterol content $\left(1268 \mathrm{mg} \cdot \mathrm{kg}^{-1}\right)$ and oil phytosterol content $\left(2257 \mathrm{mg} \cdot \mathrm{kg}^{-1}\right)$ than the other accessions. Conversely, 'Cristomorto' had significantly higher kernel phytosterol content $\left(2472 \mathrm{mg} \cdot \mathrm{kg}^{-1}\right)$, whereas both 'Cristomorto' and 'Fourcoronne' had significantly higher oil phytosterol content (4005 and $3999 \mathrm{mg} \cdot \mathrm{kg}^{-1}$, respectively). The accessions also showed great variability in their phytosterol profiles. Breeding clone 472 and 'Bartre' were characterized by the lowest $(61.7 \%)$ and highest $(81.4 \%)$ concentrations of $\beta$-sitosterol, respectively. 'G-3-3' possessed the lowest concentration of $\Delta^{5}$-avenasterol $(9.3 \%)$, whereas the highest concentrations of this phytosterol (greater than 24\%) were identified in 'Tree', Breeding clone 478, 'Ponç', and Breeding clone 472 (Table 3).
Correlation coefficients between both years were significant for kernel oil content $(r=0.64 ; P<0.01)$, kernel phytosterol content $(r=0.29 ; P<0.01)$, oil phytosterol content $(r=0.21$; $P<0.01)$, and concentrations of campesterol $(r=0.36 ; P<0.01)$, stigmasterol $(r=0.41 ; P<0.01), \beta$-sitosterol $(r=0.48 ; P<0.01)$, sitostanol $(r=0.18 ; P<0.05), \Delta^{5}$-avenasterol $(r=0.69 ; P<$ $0.01), \Delta^{5,24}$-stigmastadienol $(r=0.38 ; P<0.01), \Delta^{7}$-stigmastenol $(r=0.22 ; P<0.01)$, and $\Delta^{7}$-avenasterol $(r=0.37 ; P<0.01)$. They were not significant for $\Delta^{7}$-campesterol and clerosterol.

Taking into account only correlations observed in both years (Table 4), kernel oil content was positively correlated with kernel phytosterol content. Kernel phytosterol content was positively correlated with the concentrations of sitostanol and $\Delta^{5,24}$-stigmastadienol and negatively correlated with the concentrations of campesterol and $\beta$-sitosterol. Kernel oil content was positively correlated with the concentrations of $\Delta^{7}$-campesterol and $\Delta^{5}$-avenasterol and negatively with the concentration of $\beta$-sitosterol. The latter was negatively correlated with the concentrations of stigmasterol, $\Delta^{7}$-campesterol, $\Delta^{5}$-avenasterol, $\Delta^{5,24}$-stigmastadienol, $\Delta^{7}$-stigmastenol, and $\Delta^{7}$-avenasterol. 
Table 3. Phytosterol content in the kernel, kernel oil content, phytosterol content in the kernel oil, and concentration of $\beta$-sitosterol and $\Delta^{5}$-avenasterol in nine almond accessions with contrasting levels of phytosterol traits. ${ }^{\mathrm{z}}$

\begin{tabular}{|c|c|c|c|c|c|c|}
\hline $\begin{array}{l}\text { Accession } \\
\text { no. }\end{array}$ & $\begin{array}{c}\text { Accession } \\
\text { name }\end{array}$ & $\begin{array}{c}\text { Kernel phytosterol } \\
\left(\mathrm{mg} \cdot \mathrm{kg}^{-1} \mathrm{kernel}\right)\end{array}$ & $\begin{array}{l}\text { Oil content } \\
(\% \text { kernel })\end{array}$ & $\begin{array}{l}\text { Oil phytosterol } \\
\left(\mathrm{mg} \cdot \mathrm{kg}^{-1} \text { oil }\right)\end{array}$ & $\begin{array}{c}\beta \text {-sitosterol } \\
(\% \text { phytosterols })\end{array}$ & $\begin{array}{c}\Delta^{5} \text {-avenasterol } \\
\text { (\% phytosterols) }\end{array}$ \\
\hline 189 & Bartre & 1739 & 56.0 & 3109 & 81.4 & 10.6 \\
\hline 231 & Cristomorto & 2472 & 61.8 & 4005 & 74.1 & 12.2 \\
\hline 246 & Ponç & 2353 & 64.2 & 3670 & 65.3 & 25.2 \\
\hline 472 & Breeding clone & 1723 & 60.3 & 2855 & 61.7 & 25.4 \\
\hline 543 & G-3-3 & 1495 & 51.1 & 2940 & 76.1 & 9.3 \\
\hline
\end{tabular}

${ }^{\mathrm{z}}$ Groups with minimum and maximum values in Duncan's multiple range test $(P<0.05)$ using average values from fruit collected in 2009 and 2010. The trait for which the accession shows extreme values, both low and high, is given in bold.

The strongest positive correlations between individual phytosterols involved campesterol with both stigmasterol and clerosterol, stigmasterol with clerosterol, $\Delta^{5,24}$-stigmastadienol with stigmasterol, $\Delta^{7}$-campesterol, clerosterol, $\Delta^{7}$-stigmastenol and $\Delta^{7}$-avenasterol, and $\Delta^{7}$-stigmastenol with $\Delta^{7}$-avenasterol (Table 4).

\section{Discussion}

Previous studies have identified large genetic variation in oil content, fatty acid composition (Kodad et al., 2011; Kodad and Socias i Company, 2008), and tocopherol content and composition (Kodad et al., 2006) in almond germplasm. The present study, based on a large and geographically diverse germplasm collection, has shown that almond germplasm also contains large variation in free and esterified phytosterol content and profile. The accession with maximum kernel phytosterol content had $2472 \mathrm{mg} \cdot \mathrm{kg}^{-1}$ as a 2 -year average compared with a maximum content of $2107 \mathrm{mg} \cdot \mathrm{kg}^{-1}$ previously reported. It is important to note that the method used in the present research, based on the analysis of almond kernels, does not measure steryl glycosides and acylated steryl glycosides, which account for $\approx 22 \%$ of total phytosterols in almond kernels (Phillips et al., 2005a).

The phytosterol fraction of all accessions was dominated by $\beta$-sitosterol, whereas $\Delta^{5}$-avenasterol was in all cases the second most abundant phytosterol, which is in agreement with previous studies (Dulf et al., 2010; Normén et al., 2007; Phillips et al., 2005a, 2005b; Robbins et al., 2011) but in disagreement with other studies in which $\Delta^{5}$-avenasterol was not identified or it was found in lower proportions (Cherif et al., 2009; Maguire et al., 2004; Miraliakbari and Shahidi, 2008). Compared with a maximum concentration of $12.9 \% \Delta^{5}$-avenasterol in the literature (Normén et al., 2007), several accessions contained a much greater concentration of this phytosterol, up to $25.4 \%$ as a 2-year average. To our knowledge no similarly high levels of $\Delta^{5}$-avenasterol have been reported for any other tree nut. Robbins et al. (2011) reported a maximum average value of $16.8 \%$ for pine nut (Pinus L.). $\Delta^{5}$-avenasterol is a major phytosterol in oats (Avena sativa L.), accounting for $\approx 30 \%$ (Määttä et al., 1999). High levels of $\Delta^{5}$-avenasterol up to $36 \%$ of the sterol fraction have also been reported in olive (Olea europaea L.) oil (Boskou, 2011). Whereas most phytosterols have no antioxidant effect, those containing an ethylidene group in the side chain such as $\Delta^{5}$-avenasterol or $\Delta^{7}$-avenasterol are effective antioxidants at high temperatures, because they protect the oil against polymerization and also retard the loss of tocopherols (Rossell, 2001). To our knowledge nutritional implications of elevated $\Delta^{5}$-avenasterol levels have not been investigated; hence, the availability of almond accessions with low and high levels of this phytosterol provides an excellent opportunity for such research.

Both the analysis of variance and the correlation study between the data of 2 years revealed a significant genotypic variation for phytosterol content and profile in almond germplasm. Studies of annual oilseed crops such as soybean [Glycine max (L.) Merr.] and rapeseed (Brassica napus L.) concluded a significant effect of the genotype on seed phytosterol content (Amar et al., 2008; Vlahakis and Hazebroek, 2000). In rapeseed, heritability estimates for phytosterol content ranged from 0.84 to 0.91 in three populations, suggesting that the trait is amenable to selection (Amar et al., 2008).

Kernel phytosterol content was positively correlated with kernel oil content in both years, suggesting that a simultaneous selection for both traits is feasible. A study of rapeseed found a positive correlation between oil and phytosterol content in one population, a negative correlation in another population, and absence of correlation in a third population (Amar et al., 2008). The high positive correlation between oil phytosterol content and kernel phytosterol content probably reflects the existence of much larger genetic variation in phytosterol content than in oil content within the germplasm collection. A strong positive correlation between oil and kernel phytosterol content has been reported in sunflower (Helianthus annuus L.) (Fernández-Cuesta et al., 2012). The strong negative correlation between the concentrations of the two major phytosterols $\beta$-sitosterol and $\Delta^{5}$-avenasterol, also observed in sunflower (Fernández-Cuesta et al., 2012), suggests the possibility of selecting for contrasting levels of both compounds.

Although there is some controversy on the health benefits of diet supplementation with high levels of phytosterols (Weingärtner et al., 2011), experimental evidence points to the effect of dietary phytosterols on reducing serum cholesterol levels (Plat and Mensink, 2005). The results of this research suggest that almond germplasm contains genetic variation that can be used for developing cultivars with increased levels of these compounds. Also, genetic variation for phytosterol profile, particularly for $\beta$-sitosterol and $\Delta^{5}$-avenasterol levels, indicates that selection for contrasting levels of these phytosterols is feasible, although additional information on the 


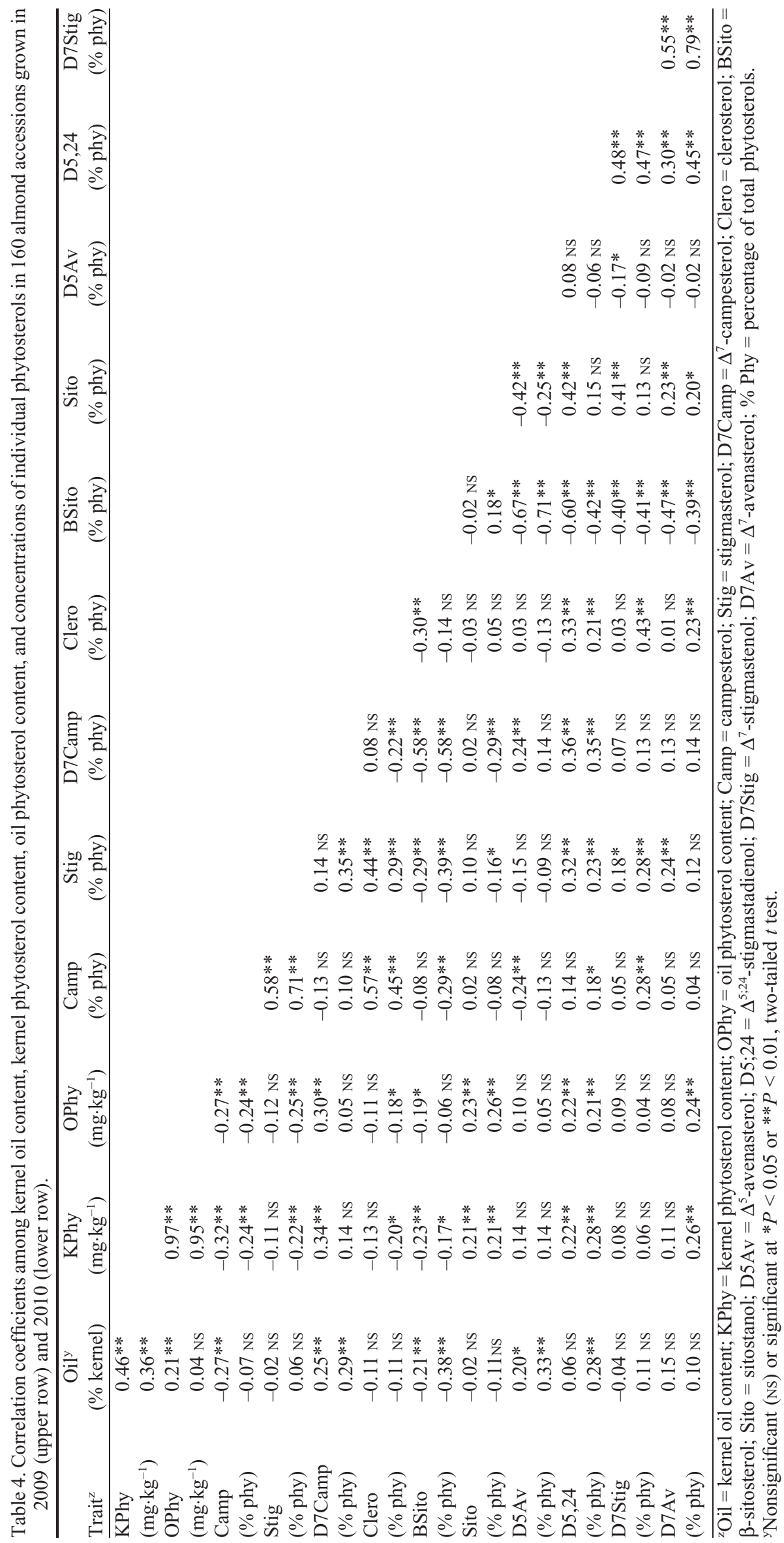


nutritional advantages of both profiles is required to define selection criteria properly.

\section{Literature Cited}

Amar, S., H.C. Becker, and C. Möllers. 2008. Genetic variation and genotype $\times$ environment interactions of phytosterol content in three doubled haploid populations of winter rapeseed. Crop Sci. 48:1000 1006.

Bacchetti, T., S. Masciangelo, V. Bicchiega, E. Bertoli, and G. Ferretti. 2011. Phytosterols, phytostanols and their esters: From natural to functional foods. Mediterranean J. Nutr. Metababolism 4:165-172.

Boskou, D. 2011. Olive oil, p. 243-271. In: Gunstone, F.D. (ed.). Vegetable oils in food technology: Composition, properties and uses. 2nd Ed. Blackwell Publishing, Chichester, UK.

Centro de Investigación y Tecnología Agroalimentaria. 2012. Phytosterol content in the kernel, kernel oil content, phytosterol content in the kernel oil, and concentration of $\beta$-sitosterol and $\Delta 5$-avenasterol in 160 accessions of the Spanish almond germplasm bank of CITA de Aragón. 24 July 2012. < http://www2.cita-aragon.es/citarea/handle/ 10532/1943>

Cherif, A., K. Belkacemi, H. Kallel, P. Angers, J. Arul, and S. Boukhchina. 2009. Phytosterols, unsaturated fatty acid composition and accumulation in the almond kernel during harvesting period: Importance for development regulation. C. R. Biol. 332:1069-1077.

Dulf, F.V., M.L. Unguresan, D.C. Vodnar, and C. Socaciu. 2010. Free and esterified sterol distribution in four Romanian vegetable oils. Notulae Botanicae Horti Agrobotanici Cluj-Napoca 38:91-97.

Espiau, M.T., J.M. Ansón, and R. Socias i Company. 2002. The almond germplasm bank of Zaragoza. Acta Hort. 591:275-278.

Fernández-Cuesta, A., M.R. Aguirre-González, M.V. Ruiz-Méndez, and L. Velasco. 2012. Validation of a method for the analysis of phytosterols in sunflower seeds. Eur. J. Lipid Sci. Technol. 114:325331.

Hartmann, M.A. 1998. Plant sterols and membrane environment. Trends Plant Sci. 3:170-175.

Kester, D.E. and R. Asay. 1975. Almonds, p. 387-419. In: Janick, J. and J.N. Moore (eds.). Advances in fruit breeding. Purdue Univ. Press, West Lafayette, IN.

Kodad, O., J.M. Alonso, M.T. Espiau, G. Estopañán, T. Juan, and R. Socias i Company. 2011. Chemometric characterization of almond germplasm: Compositional aspects involved in quality and breeding. J. Amer. Soc. Hort. Sci. 136:273-281.

Kodad, O. and R. Socias i Company. 2008. Variability of oil content and of major fatty acid composition in almond (Prunus amygdalus Batsch) and its relationship with kernel quality. J. Agr. Food Chem. 56:4096-4101.

Kodad, O., R. Socias i Company, M.S. Prats, and M.C. López-Ortiz. 2006. Variability in tocopherol concentrations in almond oil and its use as a selection criterion in almond breeding. J. Hort. Sci. Biotechnol. 81:501-507.
Lin, X., L. Ma, S.B. Racette, C.L. Spearie, and R.E. Ostlund. 2009. Phytosterol glycosides reduce cholesterol absorption in humans. Amer. J. Physiol. Gastrointest. Liver Physiol. 296:G931-G935.

Määttä, K., A.M. Lampi, J. Petterson, B.M. Fogelfors, V. Piironen, and A. Kamal-Eldin. 1999. Phytosterol content in seven oat cultivars grown at three locations in Sweden. J. Sci. Food Agr. 79:1021-1027. Maguire, L.S., S.M. O'Sullivan, K. Galvin, T.P. O'Connor, and N.M. O'Brien. 2004. Fatty acid profile, tocopherol, squalene and phytosterol content of walnuts, almonds, peanuts, hazelnuts and the macadamia nut. Intl. J. Food Sci. Nutr. 55:171-178.

Miraliakbari, H. and F. Shahidi. 2008. Lipid class compositions, tocopherols and sterols of tree nut oils extracted with different solvents. J. Food Lipids 15:81-96.

Moreau, R.A., M.J. Powell, and V. Singh. 2003. Pressurized liquid extraction of polar and nonpolar lipids in corn and oats with hexane, methylene chloride, isopropanol, and ethanol. J. Amer. Oil Chemists' Soc. 80:1063-1067.

Normén, L., L. Ellegard, H. Brants, P. Dutta, and H. Andersson. 2007. A phytosterol database: Fatty foods consumed in Sweden and the Netherlands. J. Food Compost. Anal. 20:193-201.

Phillips, K.M., D.M. Ruggio, and M. Ashraf-Khorassani. 2005a. Analysis of steryl glucosides in foods and dietary supplements by solid-phase extraction and gas chromatography. J. Food Lipids 12:124-140

Phillips, K.M., D.M. Ruggio, and M. Ashraf-Khorassani. 2005b. Phytosterol composition of nuts and seeds commonly consumed in the United States. J. Agr. Food Chem. 53:9436-9445.

Piironen, V., D.G. Lindsay, T.A. Miettinen, J. Toivo, and A.M. Lampi. 2000. Plant sterols: Biosynthesis, biological function and their importance to human nutrition. J. Sci. Food Agr. 80:939-966.

Plat, J. and R.P. Mensink. 2005. Plant stanol and sterol esters in the control of blood cholesterol levels: Mechanism and safety aspects. Amer. J. Cardiol. 96:15-22.

Robbins, K.S., E.C. Shin, R.L. Shewfelt, R.R. Eitenmiller, and R.B. Pegg. 2011. Update on the healthful lipid constituents of commercially important tree nuts. J. Agr. Food Chem. 59:12083-12092.

Rossell, J.B. 2001. Frying: Improving quality. CRC Press, Boca Raton, FL.

Socias i Company, R. and A.J. Felipe. 1992. Almond: A diverse germplasm. HortScience 27:717-718, 863.

Socias i Company, R., O. Kodad, J.M. Alonso, and T.M. Gradziel. 2008. Almond quality: A breeding perspective. Hort. Rev. 34:197-238.

U.S. Department of Agriculture. 2011. National Nutrient Database for Standard Reference, Release 24. 4 May 2012. <http://www.ars.usda. gov/ba/bhnrc/ndl>.

Vlahakis, C. and J. Hazebroek. 2000. Phytosterol accumulation in canola, sunflower, and soybean oils: Effects of genetics, planting location, and temperature. J. Amer. Oil Chemists' Soc. 77:49-53.

Weingärtner, O., C. Ulrich, D. Lütjohann, K. Ismail, S.H. Schirmer, T. Vanmierlo, M. Böhm, and U. Laufs. 2011. Differential effects on inhibition of cholesterol absorption by plant stanol and plant sterol esters in apoE $\mathrm{E}^{-/-}$mice. Cardiovasc. Res. 90:484-492. 